\title{
10 km Running Performance Predicted by a Multiple Linear Regression Model with Allometrically Adjusted Variables
}

\author{
by \\ Cesar C. C. Abad', Ronaldo V. Barros², Romulo Bertuzzi², João F. L. Gagliardi², \\ Adriano E. Lima-Silva ${ }^{3}$, Mike I. Lambert ${ }^{4}$, Flavio O. Pires ${ }^{5}$
}

The aim of this study was to verify the power of $V O_{2 m a x}$, peak treadmill running velocity (PTV), and running economy (RE), unadjusted or allometrically adjusted, in predicting $10 \mathrm{~km}$ running performance. Eighteen male endurance runners performed: 1) an incremental test to exhaustion to determine $V O_{2 m a x}$ and $P T V$; 2) a constant submaximal run at $12 \mathrm{~km} \cdot \mathrm{h}^{-1}$ on an outdoor track for RE determination; and 3) a $10 \mathrm{~km}$ running race. Unadjusted $\left(V O_{2 m a x}, P T V\right.$ and $\left.R E\right)$ and adjusted variables $\left(V O_{2 m a x} 0.72, P T V^{0.72}\right.$ and $\left.R E^{0.60}\right)$ were investigated through independent multiple regression models to predict $10 \mathrm{~km}$ running race time. There were no significant correlations between $10 \mathrm{~km}$ running time and either the adjusted or unadjusted $V_{2}$ max. Significant correlations $(p<0.01)$ were found between 10 $k m$ running time and adjusted and unadjusted RE and PTV, providing models with effect size $>0.84$ and power $>0.88$. The allometrically adjusted predictive model was composed of $P T V^{0.72}$ and $R E^{0.60}$ and explained $83 \%$ of the variance in $10 \mathrm{~km}$ running time with a standard error of the estimate (SEE) of $1.5 \mathrm{~min}$. The unadjusted model composed of a single PVT accounted for $72 \%$ of the variance in $10 \mathrm{~km}$ running time (SEE of $1.9 \mathrm{~min}$ ). Both regression models provided powerful estimates of $10 \mathrm{~km}$ running time; however, the unadjusted PTV may provide an uncomplicated estimation.

Key words: $V O_{2 m a x}$; peak of treadmill velocity; running economy; allometry.

\section{Introduction}

Endurance performance has been associated with the capacity for oxygen uptake $\left(\mathrm{VO}_{2}\right)$. As a consequence, maximal oxygen uptake $\left(\mathrm{VO}_{2 \max }\right)$ has traditionally been considered as a key variable when either prescribing training for competitive middle and long distance runners (Brandon and Boileau, 1987; Pollock, 1977), or for predicting performance in prolonged events (Midgley et al., 2006). However, the predictive power of $\mathrm{VO}_{2 \max }$ has been challenged as some studies reported low correlations between
$\mathrm{VO}_{2 \max }$ and endurance performance in trained and untrained individuals (Conley and Krahenbuhl, 1980; Noakes et al., 1990; Stratton et al., 2009). A factor which may be related to poor predictive power of $\mathrm{VO}_{2 \max }$ is the difference in body dimensions (Chamari et al., 2005; Eisenmann et al., 2001; Vanderburgh and Laubach, 2008), as studies have often not considered variations in body mass when measuring $\mathrm{VO}_{2 \max }$.

Other physiological variables, such as running economy (RE), defined as the energy

\footnotetext{
1 - Department of Physical Education, Senac University Centre, São Paulo, Brazil.

2 - School of Physical Education and Sport, University of São Paulo, Brazil.

3 - Sports Science Research Group, Department of Physical Education and Sports Science CAV, Federal University of Pernambuco, Brazil.

4 - Division of Exercise Science and Sports Medicine (ESSM), Department of Human Biology, Faculty of Health Sciences, University of Cape Town, South Africa.

5 - Exercise Psychophysiology Research Group, School of Arts, Sciences and Humanities, University of São Paulo, Brazil.
} 
demand for a given velocity of submaximal running (Saunders et al., 2004), has been associated with endurance running performance (Conley and Krahenbuhl, 1980). For example, RE predicts aerobic training effects and endurance performance in highly trained runners with comparable $\mathrm{VO}_{2 \max }$ values (Conley and Krahenbuhl, 1980). Furthermore, RE was able to detect lower changes caused by a physical training program in well trained athletes with similar $\mathrm{VO}_{2 \max }$ values (Saunders et al., 2004). However, some studies have also found low correlations between RE and endurance performance, making the predictive power of RE poor in untrained individuals (Stratton et al., 2009; Tolfrey et al., 2009). As RE is also influenced by variations in body mass, a possible explanation for the poor predictive power between RE and endurance performance may be the lack of allometric adjustment in submaximal $\mathrm{VO}_{2}$ values (Berg, 2003).

In addition to $\mathrm{VO}_{2 \max }$ and $\mathrm{RE}$, the peak treadmill running velocity (PTV), defined as the fastest speed attained and maintained for one minute in a $\mathrm{VO}_{2 \max }$ test, is also a potential predictor of endurance performance. For example, PTV predicted performance of runners in races of different distances $(r=-0.88$ to -0.94 in races of 10 $90 \mathrm{~km}$ ) (Noakes et al., 1990), as well as of an Olympic-distance National Triathlon Championship (1500 m swim, $40 \mathrm{~km}$ cycle, $10 \mathrm{~km}$ run) $(r=0.85)$ (Schabort et al., 2000). However, Legaz-Arrese et al. (2011) challenged the usefulness of the PTV to discriminate endurance performance in elite runners, as steeplechase elite runners elicited greater PTV when compared to elite marathon runners. This result contradicts the suggestion that the higher the PTV the better the endurance performance. In accordance with maximal aerobic power and RE, these results also suggest that differences in body mass may affect the PTV, as steeplechase runners were heavier than the marathoners (McLaughlin et al., 2010).

A common factor that may have affected the predictive power of $\mathrm{VO}_{2 \max }, \mathrm{RE}$ and PTV in those studies was the lack of allometric correction according to variations in body mass (Conley and Krahenbuhl, 1980; Legaz-Arrese et al., 2011; Noakes et al., 1990; Stratton et al., 2009). Given the non-linear relationship between body size and a metabolic rate, some studies have used allometric scaling of body mass to improve the predictive power of maximal and submaximal $\mathrm{VO}_{2}$ values (Agutter and Wheatley, 2004; Bergh et al., 1991; McLaughlin et al., 2010). Therefore, the lack of allometric scaling may have biased results of those studies, decreasing the power of $\mathrm{VO}_{2 \max } \mathrm{RE}$ and PTV in predicting endurance performance. The laws of proportionalities and scaling support the notion that $\mathrm{VO}_{2}$ values are proportional to body mass raised to the power between 0.60 and 0.75 (Chamari et al., 2005; Eisenmann et al., 2001; Vanderburgh and Laubach, 2008). Furthermore, others have also suggested allometric scaling on mechanical variables when predicting performance (Crewther et al., 2011; Vanderburgh and Laubach, 2008). For example, a greater predictive power of cycling endurance performance was found when the peak power output determined in a preliminary $\mathrm{VO}_{2 \max }$ test was corrected by an allometric exponent (Lamberts et al., 2012). However, no study has yet verified whether running endurance performance is better predicted by PTV values after allometric adjustments for body mass.

Despite the controversy, the prediction of running endurance performance by $\mathrm{VO}_{2 \max }$ test variable(s) still remains as current debate, and recent studies have investigated the correlations between $\mathrm{VO}_{2 \max }$ test outputs and middle and longdistance running performance (Legaz-Arrese et al., 2011; McLaughlin et al., 2010; Stratton et al., 2009). For example, McLaughlin et al. (2010) submitted 17 runners to a $\mathrm{VO}_{2 \max }$ test, and using a stepwise regression model they found that the velocity at $\mathrm{VO}_{2 \max }$ was the best predictor of a 16 $\mathrm{km}$ running time trial. However, this study only analyzed unadjusted variables so it was not determined whether allometrically adjusted $\mathrm{VO}_{2 \max }$ and RE, together with the PTV, would have improved the endurance performance prediction.

Therefore, the objective of this study was to develop a multiple regression model derived from allometrically adjusted $\mathrm{VO}_{2 \max } \mathrm{RE}$ and PTV to determine whether the model would predict endurance performance with greater accuracy than the existing predictions. Considering that $\mathrm{VO}_{2 \max }, \mathrm{RE}$ and PTV without allometric adjustments had been used to predict endurance performance with varying degrees of accuracy, we hypothesized that these variables 
would improve the endurance performance prediction when adjusted by allometric scaling. A $10 \mathrm{~km}$ running race was selected as the performance measure taking into account that this is a race distance that several long distance runners $(5 \mathrm{~km}, 10 \mathrm{~km}$, half-marathon, marathon, ultra-marathon and cross-country runners) compete in.

\section{Material and Methods}

\section{Participants}

Eighteen male endurance runners (29.1 \pm 5.1 years old, $66.9 \pm 10.3 \mathrm{~kg}$ and $173.9 \pm 7.30 \mathrm{~cm}$ ) volunteered to participate in the study. After explanation of all experimental procedures, possible risks and benefits, each runner gave his written informed consent. They were regional competitive runners with an uninterrupted training experience of $\geq 3$ years, best $10 \mathrm{~km}$ running time $\leq 40 \mathrm{~min}$ and weekly training frequency of $\geq 3$ sessions. The study was approved by the Ethics Committee of the University of São Paulo, which conformed to the Declaration of Helsinki.

\section{Procedures}

Runners visited the laboratory on three different occasions, separated by at least $48 \mathrm{~h}$, within a 14 day period. Each runner completed: 1) a laboratory maximal incremental test to exhaustion on a treadmill for the determination of $\mathrm{VO}_{2 \max }$ and PTV; 2) a $12 \mathrm{~km} \cdot \mathrm{h}^{-1}$ constant running test on an outdoor track for RE determination; and 3) a $10 \mathrm{~km}$ running race completed as a competitive simulation on the outdoor track to determine the endurance running performance. Subjects were asked to avoid intense training during the $24 \mathrm{~h}$ before the procedures, and maintain a habitual diet and training for the duration of the study. All tests were performed at the same time of the day. The tests performed on the outdoor track had windless conditions, $60 \%$ air humidity and temperature ranging from 19 to $22^{\circ} \mathrm{C}$.

\section{Maximal Incremental Test on a Treadmill}

After a 3 min warm-up walking at $6 \mathrm{~km} \cdot \mathrm{h}^{-}$ 1 , the test was immediately started with $1.2 \mathrm{~km} \cdot \mathrm{h}^{-1}$ increases every 3 min until volitional exhaustion. The treadmill gradient was maintained at $1 \%$ elevation, thus simulating the outdoor running energy cost (Jones and Doust, 1996). Verbal encouragement was provided throughout the test to ensure the attainment of maximal effort, and the exhaustion was identified when runners were not able to maintain the running pace. Individuals wore a mask (Hans Rudolph ${ }^{\circledR}$, Kansas City, MO, USA) throughout the test to measure the pulmonary $\mathrm{VO}_{2} . \mathrm{VO}_{2}$ was recorded breath-bybreath with a gas analyzer (K4b2 ${ }^{2}$ Cosmed, Italy), previously calibrated according to the manufacturer's instructions. Briefly, $\mathrm{O}_{2}$ and $\mathrm{CO}_{2}$ sensors were calibrated using ambient air and a known composition gas $\left(12 \% \mathrm{O}_{2}\right.$ and $\left.5 \% \mathrm{CO}_{2}\right)$, while the turbine flowmeter was calibrated using a 3-L syringe (Quinton Instruments, USA). Thereafter, breath-by-breath $\mathrm{VO}_{2}$ data were converted to $10 \mathrm{~s}$ averages. Similarly to previous research (Ingham et al., 2008; Weston et al., 2002), $\mathrm{VO}_{2 \max }$ was defined as the highest value reached for $30 \mathrm{~s}$ during the last stage of the incremental test. Furthermore, the highest velocity attained during the last stage fully completed was recorded as PTV.

\section{Running Economy Test}

Runners performed an individual $10 \mathrm{~min}$ warm-up composed of stretching and low intensity running. Thereafter they performed a 6 min running bout at $12 \mathrm{~km} \cdot \mathrm{h}^{-1}$ on a $400 \mathrm{~m}$ outdoor track, while the pulmonary $\mathrm{VO}_{2}$ was taken breathby-breath $\left(\mathrm{K}_{4} \mathrm{~b}^{2}\right.$, Cosmed, Italy). As part of their training they used to run on an outdoor track at similar velocities, so that we hypothesized that improved RE may be found during RE tests performed on outdoor tracks. The $12 \mathrm{~km} \cdot \mathrm{h}^{-1}$ velocity was controlled by an evaluator and represented an intensity which was under the lactate threshold velocity for all the runners in the study. In previous analyses using velocities from 9 to $15 \mathrm{~km} \cdot \mathrm{h}^{-1}$, we verified that RE obtained at 12 $\mathrm{km} \cdot \mathrm{h}^{-1}$ presented the highest correlation with endurance performance indices $(r=0.92 ; p<0.01)$, when compared to RE obtained at other velocities (Lima-Silva et al., 2010). The gas analyzer was calibrated before every test as described for the laboratory test. After converting breath-by-breath $\mathrm{VO}_{2}$ measures to $10 \mathrm{~s}$ averages, RE was determined as the mean $\mathrm{VO}_{2}$ response during the last $30 \mathrm{~s}$ of the $12 \mathrm{~km} \cdot \mathrm{h}^{-1}$ running bout.

\section{$10 \mathrm{~km}$ Running Race}

After a self-paced warm-up, runners completed a $10 \mathrm{~km}$ running race on an outdoor $400 \mathrm{~m}$ track. To avoid alterations in performance as a consequence of different pacing strategies 
influenced by other runners, each runner completed the $10 \mathrm{~km}$ distance alone. The participants were asked to complete the $10 \mathrm{~km}$ as if it was a competition - the difference being that there was no feedback based on elapsed time or the heart rate (HR). They were verbally encouraged throughout the race. The time to complete the $10 \mathrm{~km}$ running race was measured manually by a digital chronometer.

\section{Statistical Analyses}

After determination of $\mathrm{VO}_{2 \max }$ PTV and $\mathrm{RE}$, as described in the former sections, these variables were allometrically adjusted based on exponents previously documented (Chamari et al., 2005; Eisenmann et al., 2001; Markovic et al., 2007), as a large sample size was not available in the present study. Thus, a number of exponents ranging from 0.60 to 0.75 were tested before the identification of exponents that provided the highest correlation with the dependent variable (i.e. running time). Following this, a 0.60 exponent was used on RE data (RE 0.60 , expressed in $\mathrm{ml} / \mathrm{kg}^{0.60} / \mathrm{min}$ ), while a 0.72 exponent was used to correct $\mathrm{VO}_{2 \max } \quad\left(\mathrm{VO}_{2 \max } 0.72\right.$, expressed in $\mathrm{ml} / \mathrm{kg}^{0.72} / \mathrm{min}$ ) and PTV data (PTV0.72, expressed in $\mathrm{km} / \mathrm{h} / \mathrm{kg}^{0.72}$ ). Although a theoretical 0.66 exponent had been suggested for $\mathrm{VO}_{2 \max }$ values (Vanderburgh and Laubach, 2008), previous studies reported different empirical exponents ranging from 0.60 to 0.75 (Chamari et al., 2005; Eisenmann et al., 2001; Markovic et al., 2007). Furthermore, we used a 0.72 exponent for PVT as no correction had been reported for this variable (the rationale was that PTV is a maximal variable associated with $\mathrm{VO}_{2 \max }$ values).

Both groups of variables, unadjusted and adjusted by allometric exponents, were used separately to obtain two different multiple linear regression models. The Gaussian distribution was initially verified by the Shapiro-Wilk test, and a normal distribution was ensured for all independent and dependent variables. Multiple regression models based on unadjusted variables (without allometric correction) and adjusted variables (body mass scaled by 0.60 for RE and 0.72 for $\mathrm{VO}_{2 \max }$ and PVT) were obtained separately to predict the time to complete the $10 \mathrm{~km}$ run.

The Pearson's correlation coefficient was used to verify which variable(s) would be initially considered in these regression models. Based on partial correlations, collinearity and variance inflation factor principles, multiple stepwise regressions selected the group of independent(s) variable(s) which accounted for the greatest variation in the dependent variable and provided the lowest standard error of estimate (SEE) (Hair et al., 2009). Whilst $\mathrm{VO}_{2 \max }, \mathrm{RE}$ and PTV, unadjusted and adjusted by allometric exponents, were independent variables, time to complete 10 $\mathrm{km}$ running was the dependent variable. In all analyses the statistical significance was set at 5\% $(p<0.05)$ and final predictive models were accepted only if power and effect size (ES) were $\geq$ 0.80 . The ES, expressed as the Pearson's correlation coefficient, was interpreted as small ( $\mathrm{r}$ $\leq 0.20)$, moderate $(0.21>\mathrm{r}<0.79)$ and large $(\mathrm{r} \geq$ 0.80) (Cohen, 1988).

\section{Results}

Runners completed the $10 \mathrm{~km}$ running race within $37.8 \mathrm{~min}( \pm 3.4)$, with mean velocity of $16.0 \mathrm{~km} \cdot \mathrm{h}^{-1}( \pm 1.4)$. Table 1 presents values of $\mathrm{VO}_{2 \max }, \mathrm{RE}$ and PTV variables, unadjusted and adjusted by allometric exponents.

There were no significant correlations between the time to complete the $10 \mathrm{~km}$ running race and $\mathrm{VO}_{2 m a x}$, either adjusted or unadjusted by the 0.72 exponent. Therefore, $\mathrm{VO}_{2 \max }$ did not contribute to the initial regression stepwise models. In contrast, significant correlations were observed between the time to complete the $10 \mathrm{~km}$ run and RE and PTV, either unadjusted or adjusted by 0.60 and 0.72 allometric exponents, respectively (Table 2). Thus, these variables were utilized in the initial predictive models of $10 \mathrm{~km}$ running performance.

Adjusted and unadjusted final multiple stepwise regression models were obtained with large effect size from 0.84 to 0.94 (expressed as the Pearson's coefficient) and power ranging from 0.88 to 0.99 . When using variables without allometric scaling, the final predictive model was obtained by inserting PTV as the single best predictor so that a model with PTV accounted for $72 \%$ of the variance in the time to complete the 10 $\mathrm{km}$ running race. When SEE was expressed relative to the mean time to complete $10 \mathrm{~km}$ running, the predictive model obtained with the single PTV produced a SEE of $4.9 \%$ (1.9 min).

Analysis with allometrically adjusted variables showed that both the PTV and RE (PTV 0.72 and $R E^{0.60}$ ) were inserted into the final stepwise 
predictive model. This adjusted final predictive model accounted for $83 \%$ of the variance in the time to complete the $10 \mathrm{~km}$ run, with a SEE of
$4.0 \%$ (1.5 min). Table 3 presents the coefficients obtained in both unadjusted and adjusted final multiple regression models.

\begin{tabular}{|c|c|c|c|c|}
\hline \multirow{2}{*}{\multicolumn{5}{|c|}{$\begin{array}{c}\text { Table } \mathbf{1} \\
\text { Values of } V O_{2 m a x}, R E \text { and } P T V \text {, adjusted and unadjusted by allometric exponents. }\end{array}$}} \\
\hline & & & & \\
\hline & Mean $( \pm$ SD) & Minimum & Maximum & $95 \% \mathrm{CI}$ \\
\hline $\mathrm{VO}_{2 \max }(\mathrm{ml} / \mathrm{kg} / \mathrm{min})$ & $62.5 \pm 7.0$ & 47.9 & 77.9 & $59.3-65.6$ \\
\hline $\mathrm{VO}_{2 \max } 0.72\left(\mathrm{ml} / \mathrm{kg}^{0.72} / \mathrm{min}\right)$ & $156.8 \pm 17.3$ & 132.9 & 182.1 & $149.0-163.8$ \\
\hline $\mathrm{RE}(\mathrm{ml} / \mathrm{kg} / \mathrm{min})$ & $2648.2 \pm 573.9$ & 1847.0 & 4003.0 & $2390.1-2906.3$ \\
\hline $\mathrm{RE}^{0.60}\left(\mathrm{ml} / \mathrm{kg}^{0.60} / \mathrm{min}\right)$ & $107.3 \pm 51.6$ & 157.7 & 111.0 & $102.8-115.0$ \\
\hline PVT $(\mathrm{km} / \mathrm{h})$ & $17.3 \pm 0.9$ & 15.1 & 18.0 & $16.8-17.7$ \\
\hline PVT $\left(\mathrm{km} / \mathrm{kg}^{0.72} / \mathrm{h}\right)$ & $0.9 \pm 0.1$ & 1.0 & 0.6 & $0.8-0.9$ \\
\hline \multicolumn{5}{|c|}{$\# V O_{2 m a x}$ - maximal oxygen uptake; $R E$ - running economy; } \\
\hline
\end{tabular}

\begin{tabular}{|c|c|c|c|c|c|c|}
\hline \multicolumn{7}{|c|}{$\begin{array}{c}\text { Correlation coefficients between time to complete the } 10 \mathrm{~km} \mathrm{run} \\
\text { and variables with or without allometric correction. }\end{array}$} \\
\hline & $\begin{array}{c}\mathrm{VO}_{2 \max } \\
(\mathrm{ml} / \mathrm{kg} / \mathrm{min})\end{array}$ & $\begin{array}{c}\mathrm{RE} \\
(\mathrm{ml} / \mathrm{kg} / \mathrm{min})\end{array}$ & $\begin{array}{c}\text { PTV } \\
(\mathrm{km} / \mathrm{h})\end{array}$ & $\begin{array}{c}\mathrm{VO}_{2 \max } \\
\left(\mathrm{ml} / \mathrm{kg}^{0.72} / \mathrm{min}\right)\end{array}$ & $\begin{array}{c}\mathrm{RE} \\
\left(\mathrm{ml} / \mathrm{kg}^{0.60} / \mathrm{min}\right)\end{array}$ & $\begin{array}{c}\text { PTV } \\
\left(\mathrm{km} / \mathrm{kg}^{0.72} / \mathrm{h}\right)\end{array}$ \\
\hline $\begin{array}{l}10 \mathrm{~km} \text { run } \\
(\mathrm{min})\end{array}$ & -0.33 & $0.67 \mathrm{~b}$ & $-0.85^{b}$ & -0.47 & $0.74^{\mathrm{b}}$ & $-0.66^{b}$ \\
\hline $\begin{array}{l}\mathrm{VO}_{2 \max } \\
(\mathrm{ml} / \mathrm{kg} / \min )\end{array}$ & 1 & -0.42 & 0.42 & $0.86^{\mathrm{b}}$ & -0.38 & 0.41 \\
\hline $\begin{array}{l}\mathrm{RE} \\
(\mathrm{ml} / \mathrm{kg} / \mathrm{min})\end{array}$ & & 1 & $-0.66^{b}$ & $-0.75^{b}$ & $0.90^{\mathrm{b}}$ & $-0.89 \mathrm{~b}$ \\
\hline $\begin{array}{l}\mathrm{PTV} \\
(\mathrm{km} / \mathrm{h})\end{array}$ & & & 1 & $0.58^{a}$ & $-0.57^{a}$ & $0.81^{\mathrm{b}}$ \\
\hline $\begin{array}{l}\mathrm{VO}_{2 \max } \\
\left(\mathrm{ml} / \mathrm{kg}^{0.72} / \mathrm{min}\right)\end{array}$ & & & & 1 & $-0.58^{\mathrm{b}}$ & $0.79^{a}$ \\
\hline $\begin{array}{l}\mathrm{RE} \\
\left(\mathrm{ml} / \mathrm{kg}^{0.60} / \mathrm{min}\right)\end{array}$ & & & & & 1 & $-0.66^{b}$ \\
\hline $\begin{array}{r}\# 10 \\
\text { Sig }\end{array}$ & $\begin{array}{l}\mathrm{km} \text { run - time } \\
\text { RE - runnt } \\
\text { lificant corre }\end{array}$ & $\begin{array}{l}\text { to complete } \\
\text { ng economy; } \\
\text { ations were } r\end{array}$ & $\begin{array}{l}10 \mathrm{~km} \\
\text { TV is } p \\
\text { norted a }\end{array}$ & $\begin{array}{l}\text { un; } V O_{2 \max } \text { ma } \\
\text { ctreadmill run } \\
\text { etters } a(p<0 \text {. }\end{array}$ & $\begin{array}{l}\text { mal oxygen up } \\
\text { ing velocity. } \\
\text { ) and } b(p<0 \text {. }\end{array}$ & \\
\hline
\end{tabular}

Table 3

Final multiple stepwise regression models of the predicted time to complete the $10 \mathrm{~km}$ run

\begin{tabular}{lccccccc}
\hline Regression Model & Predictive Variables & $\mathrm{R}^{2}$ & SEE & bSTD & Power & ES & $p$ \\
\hline Unadjusted & PTV & 0.72 & 1.9 & -0.85 & 0.88 & 0.94 & $<0.001$ \\
Adjusted & PTV $^{0,72}+\mathrm{RE}^{0,60}$ & 0.83 & 1.5 & $-0.64+0.39$ & 0.99 & 0.84 & $<0.01$ \\
\hline \multicolumn{7}{c}{ \#SEE - standard error of the estimate; bSTD - beta standardized coefficient; } \\
ES - effect size of the model; PTV - peak treadmill running velocity; RE - running economy.
\end{tabular}




\section{Discussion}

Traditional aerobic indexes such as $\mathrm{VO}_{2 \max }, \mathrm{RE}$ and PTV have been used to predict endurance performance with varying degrees of accuracy. Thus, we verified if a multiple regression model derived from these indexes, allometrically adjusted, may predict endurance performance with greater accuracy. The first finding of this study was that a model incorporating PTV 0.72 and $\mathrm{RE}^{0.60}$ accounted for $83 \%$ of the variance in the time to complete the $10 \mathrm{~km}$ running race. The second finding was that a single unadjusted PTV also provided a powerful (reliable with low error of estimation) estimation of $10 \mathrm{~km}$ running performance, accounting for $72 \%$ of the variance in the time to complete the 10 $\mathrm{km}$ run. The large effect size (0.84 to 0.94) and power (0.88 to 0.99 ) indicate the power of the final stepwise regression models. These results have important practical implications, as they show that a traditional test used to assess variables associated with middle and long-distance running performance is able to provide reasonable estimation of a $10 \mathrm{~km}$ running performance.

To the best of our knowledge, only the study by Ingham et al. (2008) investigated variables allometrically adjusted to predict running performance. Given the methodological differences regarding dependent and independent variables, allometric exponents and the aerobic profile of the runners, direct comparisons between both studies are difficult. For example, Ingham et al. (2008) found that a model based on $\mathrm{VO}_{2 \max }$ and $\mathrm{RE}$ variables, corrected with a 0.35 exponent, accounted for $96 \%$ of the variance in running velocity in a $800 \mathrm{~m}$ and $1500 \mathrm{~m}$ running race. In their analysis, Ingham et al. (2008) observed that the maximal aerobic velocity, the velocity corresponding to $\mathrm{VO}_{2 \max }\left(\mathrm{VVO}_{2 \max }\right)$, did not improve the final predictive models. In contrast, our final adjusted regression model was composed of PTV and RE, without $\mathrm{VO}_{2 \max }$. What was also different to Ingham et al. (2008), who calculated the $\mathrm{vVO}_{2 \max }$ by extrapolation from submaximal intensities, was that we used the actual measured PTV as maximal aerobic velocity. In addition, we used the time to complete a longer event, a $10 \mathrm{~km}$ running race as a dependent variable, while they used the mean velocity in 800 $\mathrm{m}$ and $1500 \mathrm{~m}$ running. These aspects may have had a different effect on the correlations between dependent and independent variables, leading to different predictive models in these studies (which may also explain the absence of correlation to $\mathrm{VO}_{2 \max }$ ).

Another relevant aspect was the allometric correction, as Ingham et al. (2008) found a curvilinear relationship between dependent (i.e. running speed) and independent (i.e. $\mathrm{VO}_{2 \max }$ and $\mathrm{RE}$ ) predictor variables such that $\mathrm{VO}_{2 \text { max }}$ and $\mathrm{RE}$ values were corrected by a 0.35 exponent. Divergent to this, we found that exponents of 0.60 and 0.72 provided the best correction for $\mathrm{RE}$ and $\mathrm{VO}_{2 \max }$, respectively. It is important to point out that previous studies reported different exponents around a 0.66 proportion (Chamari et al., 2005; Eisenmann et al., 2001; Vanderburgh and Laubach, 2008), when correcting maximal and submaximal $\mathrm{VO}_{2}$ values of individuals with a similar profile. Therefore, because our sample size was not large enough to allow performing cross-validation regression diagnostics, we used this range of exponents to identify the best allometric adjustment. This approach is suggested when the simple size is limited (Hair et al., 2009; Zoeller et al., 2007).

Studies that have investigated how indices derived from $\mathrm{VO}_{2}$ max tests could predict running performance showed that unadjusted variables such as $\mathrm{VO}_{2 \max } \mathrm{RE}, \% \mathrm{VO}_{2 \max }$ at the lactate threshold and $\mathrm{vVO}_{2 m a x}$ were strongly correlated with performance in 2 mile treadmill running ( $\mathrm{R}^{2}=0.69$ to 0.87 ) (Tolfrey et al., 2009) and a $16 \mathrm{~km}$ running race $\left(\mathrm{R}^{2}=0.66\right.$ to 0.94$)$ (McLaughlin et al., 2010). However, when conducting a multiple stepwise regression model, McLaughlin et al. (2010) verified that a model that combined only unadjusted $\mathrm{VO}_{2}$ max and $\mathrm{RE}$ values best predicted the $16 \mathrm{~km}$ running performance. In that study, the inclusion of PTV did not improve the variance in performance accounted for by the model that included $\mathrm{VO}_{2 \max }$ and $\mathrm{RE}(97.3 \%)$. In contrast, the PTV was included in our final predictive adjusted model.

In the present study, the best multiple stepwise regression model obtained with a single PTV accounted for $72 \%$ of the variance in $10 \mathrm{~km}$ running time. This final predictive model was based on strict principles of partial correlation, collinearity, and a variance inflation factor (Hair et al., 2009). In accordance, each independent variable that accounted for equal variance in the 
dependent variable, having controlled the effect of other independent variables, was excluded. Thus, rather than considering the $F$ probability as a single criterion to include variables, independent variables were inserted into the final stepwise regression model only when accounting for a new portion of the variance of the dependent variable. Due to high collinearity as well as a high variance inflation factor with PTV and a low partial correlation with performance, RE was not inserted into the final stepwise model with unadjusted data. Consequently, only the unadjusted PTV predicted the $10 \mathrm{~km}$ running performance.

Similar to our results, Stratton et al. (2009) reported that PTV was the single best predictor of a $5000 \mathrm{~m}$ running performance in individuals with different conditioning states. Neither $\mathrm{VO}_{2 \max }$ nor RE was added into a stepwise regression model in that study. Together, these and other results may suggest that PTV may be considered as a good global predictor of running performance in distances from 5 to $90 \mathrm{~km}$. Perhaps the fact that PTV is related to maximal aerobic power, the anaerobic metabolism, neuromuscular factors and motivation (Noakes et al., 1990; Stratton et al., 2009) may explain the ability of the PTV to predict endurance running performance.

Our results have practical implications. Due to the simple and uncomplicated calculations, the predictive model obtained with a single PTV may be preferable when compared to the allometric adjusted model. In fact, a model composed of PTV and RE allometrically adjusted (PTV 0.72 and RE 0.60 , respectively) would demand submaximal and maximal incremental tests to improve the estimates of the $10 \mathrm{~km}$ running performance by only $0.9 \%$. In contrast, a single $\mathrm{VO}_{2 \max }$ incremental test may be feasible as this could provide a reliable estimation of endurance performance through a single PTV. Although one could argue that a $10 \mathrm{~km}$ running time trial is more specific than a $\mathrm{VO}_{2 \max }$ test when estimating running performance, it is important to note that $\mathrm{VO}_{2 \max }$ tests are traditionally used to assess physiological indices of fitness evaluation and endurance training prescription. Thus, indices such as $\mathrm{VO}_{2 \max }$ and aerobic/anaerobic thresholds, often used to determine different training zones (Legaz-Arrese et al., 2011), may be obtained together with a $10 \mathrm{~km}$ running performance estimate through a single test. Furthermore, a $\mathrm{VO}_{2 \text { max }}$ test may be feasible, as this can be performed regardless of variations in environment conditions, such as weather and terrain.

\section{Conclusion}

A multiple regression model obtained with PTV and RE, but not $\mathrm{VO}_{2 \max }$, provided powerful estimates of $10 \mathrm{~km}$ running performance when these variables were allometrically adjusted by 0.72 and 0.60 exponents, respectively. However, our results also showed that a single unadjusted PTV may provide a reasonable and uncomplicated estimate of endurance performance in long-distance runners, thus making the allometric adjustment unnecessary in practical terms.

\section{References}

Agutter PS, Wheatley DN. Metabolic scaling: consensus or controversy? Theor Biol Med Model, 2004; 1: 13

Berg K. Endurance training and performance in runners: research limitations and unanswered questions. Sports Med, 2003; 33(1): 59-73

Bergh U, Sjödin B, Forsberg A, Svedenhag J. The relationship between body mass and oxygen uptake during running in humans. Med Sci Sports Exerc, 1991; 23(2): 205-211

Brandon LJ, Boileau RA. The contribution of selected variables to middle and long distance run performance. J Sports Med Phys Fitness, 1987; 27(2): 157-164

Chamari K, Moussa-Chamari I, Boussaïdi L, Hachana Y, Kaouech F, Wisløff U. Appropriate interpretation of aerobic capacity: allometric scaling in adult and young soccer players. Br J Sports Med, 2005; 39(2): 97101

Cohen J. Statistical Power Analysis for the Behavioral Sciences. $2^{\text {nd }}$ ed. Hillsdale, New Jersey: Lawrence Erlbaum; 1988

Conley DL, Krahenbuhl GS. Running economy and distance running performance of highly trained athletes. 
Med Sci Sports Exerc, 1980; 12(5): 357-360

Crewther BT, McGuigan MR, Gill ND. The ratio and allometric scaling of speed, power, and strength in elite male rugby union players. J Strength Cond Res, 2011; 25(7): 1968-1975

Eisenmann JC, Pivarnik JM, Malina RM. Scaling peak $\mathrm{VO}_{2}$ to body mass in young male and female distance runners. J Appl Physiol, 2001; 90(6): 2172-2180

Ingham SA, Whyte GP, Pedlar C, Bailey DM, Dunman N, Nevill AM. Determinants of 800-m and 1500-m running performance using allometric models. Med Sci Sports Exerc, 2008; 40(2): 345-350

Hair JF, Black WC, Babin BJ, Anderson RE. Multivariate Data Analysis. Englewood Cliffs, New Jersey; 2009

Jones AM, Doust JH. A 1\% treadmill grade most accurately reflects the energetic cost of outdoor running. J Sports Sci, 1996; 14(4): 321-327

Lamberts RP, Lambert MI, Swart J, Noakes TD. Allometric scaling of peak power output accurately predicts time trial performance and maximal oxygen consumption in trained cyclists. Br J Sports Med, 2012; 46(1): 36-41

Legaz-Arrese A, Munguía-Izquierdo D, Carranza-García LE, Reverter-Masía J, Torres-Dávila CG, MedinaRodríguez RE. The validity of incremental exercise testing in discriminating of physiological profiles in elite runners. Acta Physiol Hung, 2011; 98(2): 147-156

Lima-Silva AE, Bertuzzi RC, Pires FO, Barros RV, Gagliardi JF, Hammond J, Kiss MA, Bishop DJ. Effect of performance level on pacing strategy during a $10 \mathrm{~km}$ running race. Eur J Appl Physiol, 2010; 108(5): $1045-53$

Markovic G, Vucetic V, Nevill AM. Scaling behaviour of VO2 in athletes and untrained individuals. Ann Hum Biol, 2007; 34(3): 315-328

McLaughlin JE, Howley ET, Bassett DR Jr, Thompson DL, Fitzhugh EC. Test of the classic model for predicting endurance running performance. Med Sci Sports Exerc, 2010; 42(5): 991-997

Midgley AW, McNaughton LR, Wilkinson M. Is there an optimal training intensity for enhancing the maximal oxygen uptake of distance runners?: empirical research findings, current opinions, physiological rationale and practical recommendations. Sports Med, 2006; 36(2): 117-132

Noakes TD, Myburgh KH, Schall R. Peak treadmill running velocity during the VO2 max test predicts running performance. J Sports Sci, 1990; 8(1): 35-45

Pollock ML. Submaximal and maximal working capacity of elite distance runners. Part I: Cardiorespiratory aspects. Ann N Y Acad Sci, 1977; 301: 310-322

Saunders PU, Pyne DB, Telford RD, Hawley JA. Factors affecting running economy in trained distance runners. Sports Med, 2004; 34(7): 465-485

Schabort EJ, Killian SC, St Clair Gibson A, Hawley JA, Noakes TD. Prediction of triathlon race time from laboratory testing in national triathletes. Med Sci Sports Exerc, 2000; 32(4): 844-849

Stratton E, O'Brien BJ, Harvey J, Blitvich J, McNicol AJ, Janissen D, Paton C, Knez W. Treadmill Velocity Best Predicts 5000-m Run Performance. Int J Sports Med, 2009; 30(1): 40-45

Tolfrey K, Hansen SA, Dutton K, McKee T, Jones AM. Physiological correlates of 2-mile run performance as determined using a novel on-demand treadmill. Appl Physiol Nutr Metab, 2009; 34(4): 763-772

Vanderburgh PM, Laubach LL. Body mass bias in a competition of muscle strength and aerobic power. $J$ Strength Cond Res, 2008; 22(2): 375-382

Weston SB, Gray AB, Schneider DA, Gass GC. Effect of ramp slope on ventilation thresholds and $\mathrm{VO}_{2 p e a k}$ in male cyclists. Int J Sports Med, 2002; 23(1): 22-27

Zoeller RF, Ryan ED, Gordish-Dressman H, Price TB, Seip RL, Angelopoulos TJ, Moyna NM, Gordon PM, Thompson PD, Hoffman EP. Allometric scaling of biceps strength before and after resistance training in men. Med Sci Sports Exerc, 2007; 39(6): 1013-1019

\section{Corresponding author:}

Flavio Oliveira Pires

School of Arts, Sciences and Humanities, University of São Paulo, 1000 Arlindo Béttio Av, Ermelino

Matarazzo, São Paulo (SP), Brazil, Postal Code 03828-000

Phone: 55+11+30918836

E-mail: piresfo@usp.br 